\title{
O PROFESSOR JOSÉ FERNANDES PONTES E A MEDICINA SOCIOPSICOSSOMÁTICA
}

Nos idos de 1947 o Professor José Fernandes Pontes, em sua Tese de Livre-Docência, escrevia que em muitas alterações gastrointestinais, a eclosão e/ou surgimento de sintomas não estavam na dependência, apenas, de fatores microbianos ou parasitários, mas sofriam uma determinação significativa de fatores emocionais.

É importante destacar que tais afirmações datam de 1947, o que demonstra o pioneirismo e a coragem intelectual deste enunciado. Note-se que a American Psychosomatic Association havia sido fundada poucos anos antes e a Associação Brasileira de Medicina Psicossomática "somente" surgiria em 1964, tendo o Prof. Pontes como um de seus fundadores e, em momento posterior, seu Presidente.

Sua vida profissional encarna e representa a história da Medicina Psicossomática, naquilo que mais a caracteriza: a pesquisa e a prática da interdisciplinaridade e das conexões sociopsicossomáticas no processo saúde-doença.

O ano de 1947 foi o anúncio de uma convicção: a promoção de saúde deveria ser pensada e praticada em uma perspectiva biopsicossocial ou sociopsicossomática.

Desta forma, inicia no recém fundado Serviço de Gastroenterologia do Hospital das Clínicas da Faculdade de Medicina da Universidade de São Paulo, em 1957, a construção de trabalho multidisciplinar que congregava médicos (inclusive residentes), psicanalistas, entre outros profissionais. Este serviço tinha como escopo prestar assistência integral aos pacientes, o que foi posteriormente desenvolvido e consolidado no Instituto de Gastroenterologia de São Paulo/Instituto Brasileiro de Estudos e Pesquisas de Gastroenterologia - IGESP/ IBEPEGE fundados pelo Prof. Pontes.

Foi um momento caracterizado por muitas descobertas e constatações, com a inclusão da Psicanálise no raciocínio clínico, o que permitiu o desenvolvimento de uma postura diferenciada frente ao paciente, sem deixar de lado os instrumentos de avaliação clínica como o palpar, percutir e auscultar. $\mathrm{O}$ ouvir assume lugar privilegiado, levando em consideração a associação de idéias, a história de vida, seus aspectos emocionais e manifestações inconscientes; a forma de ser, sentir e reagir de uma pessoa foi incluída nesse raciocínio clínico.

Outra influência importante foi a da Medicina Antropológica de Lain Entralgo e Von Weizsäcker. Esta escola propõe que o estudo da vida e portanto, do processo de adoecer, deve incluir dupla determinação: uma de ordem biológica e outra de ordem biográfica. Ou seja, que na compreensão mais ampla e completa do processo saúde-doença devem ser incorporados ao pensamento clínico aspectos relacionados à biologia e a história de vida do paciente.

Fundamentado em sólida formação médica, Prof. Pontes pôde acrescentar ao raciocínio biofisicoquímico (como gostava de dizer) de medicina voltada exclusivamente para uma ciência do corpo, um conjunto de conhecimentos advindos da Psicanálise e da Medicina Antropológica. Sob esta perspectiva de observação pôde perceber que o adoecer não era um acontecimento casual na vida de uma pessoa, mas que tinha sentido, que podia ser percebido no discurso dos pacientes, no relato de suas vidas, revelando significados, até então ocultos, que estavam inscritos na sua biografia. Poderoso instrumento semiológico foi então desenvolvido para esta observação a anamnese biográfica.

Importante frisar que o Prof. Pontes manteve-se na prática da Clínica Médica e da Gastroenterologia e construiu seu conhecimento a partir desta experiência. Diferentemente de outros nomes importantes para a Psicossomática no Brasil, não se afastou da atividade, vale lembrar que dos seis primeiros presidentes que a Associação Brasileira de Medicina Psicossomática apenas o Prof. Pontes manteve-se fiel a ela, o que o colocava em posição privilegiada de observação na interação mente-corpo. Os doentes que o procuravam apresentavam-se com queixas predominantemente orgânicas. Uma história médica minuciosamente colhida, a atenção à vida mental e aos aspectos psicossociais, seu acompanhamento clínico (muitos deles em análise) permitiu a observação de forma bastante expressiva da integração psicossomática. Manteve-se na Clínica Médica, incluiu a Psicanálise como referencial de compreensão da pessoa e de seu processo de adoecer, mas não reduziu a Psicossomática à Psicanálise.

Dentro destes princípios de assistência integral aos pacientes, constrói o IGESP/IBEPEGE, junto a outros colegas, que se torna pólo formador de profissionais e de construção de conhecimento na Gastroenterologia e na Psicossomática, que no seu entendimento, eram indissociáveis.

Nos cursos de pós-graduação em Gastroenterologia - especialização e mestrado - a disciplina de Psicossomática 
era obrigatória e o enfoque a ela dado era tão proeminente, que se transformou em curso aberto a todos os profissionais de saúde; tornou-se, assim, espaço importante para a formação de abordagem Psicossomática, inicialmente com 1 ano e a seguir, 2 anos de duração. As aulas, seminários, supervisões de atendimento, discussões de casos clínicos, se constituíam em exercícios de ensino e prática multi e interdisciplinares.

Esta trajetória, aqui muito sumarizada, sinaliza o porquê da mudança posterior da denominação do curso de Psicossomática do IBEPEGE: um conjunto de conhecimentos foi assimilado, os fundamentos básicos permaneciam, mas outros saberes foram incorporados, progressivamente. Esta evolução não se evidenciava no título original do curso e não mais transmitia a concepção que fora construída, da atenção integral aos pacientes e familiares. Num sábado, em reunião habitual do grupo de Psicossomática que se realizava em sua residência, em atmosfera impregnada por sua imensa biblioteca, Prof. Pontes fez uma pergunta, que na verdade era uma comunicação: "Estou pensando em denominar o nosso curso de Abordagem Sociopsicossomática, o que vocês acham?". Era fácil concordar, já que há muito falávamos de uma forma de compreensão e intervenção biopsicossocial no processo saúde-doença. Daí a inclusão do elemento "Sócio" à Psicossomática.

É necessário destacar que este grande edifício de conhecimentos que o Prof. Pontes denominou de Abordagem Sociopsicossomática foi construído a partir da prática, de histórias clínicas minuciosamente colhidas e avaliadas, segundo as necessidades de investigação que incluía instrumentos laboratoriais e tecnológicos da Medicina, integrado aos aspectos psicossociais. Parte desta experiência está relatada na revista Arquivos de Gastroenterologia, nas
Discussões de Observações Clínicas do IBEPEGE, além de outros artigos ali publicados.

Prof. Pontes sempre impressionou por sua enorme disponibilidade e capacidade de ensinar. Foram inúmeras as aulas e conferências que proferiu, vale destacar sua Conferência Magna no XIII Congresso Panamericano de Gastroenterologia que se realizou em Buenos Aires, em 1973 e que tinha como título: A integração dos sintomas nos planos somático e psicoemocional. Participou de forma bastante ativa, enquanto lhe foi possível, de todos os congressos da Associação Brasileira de Medicina Psicossomática, onde foi homenageado inúmeras vezes.

Ministrou uma aula histórica, em um dos Congressos, munido apenas de uma lousa e giz, mas que galvanizou a atenção da enorme platéia presente, não só pela excelência da didática e capacidade de transmissão do conhecimento, mas também, e principalmente, pelo conteúdo clínico e humanístico. Grande parte do conteúdo desta aula está presente no capítulo: Medicina sociopsicossomática em Gastroenterologia do Livro Gastroenterologia Clínica, de Renato Dani e Luiz de Paula Castro.

No exercício da docência fazia a distinção entre o mestre e o professor, a ele bastante pertinente. Isto é retratado no prefácio que escreveu para a $4^{a}$ edição do livro A medicina da pessoa de Danilo Perestrello: "Professor informa e o Mestre faz aprender; quantos dele se aproximaram sabem que, além de ensinar, sempre tem despertado nas novas gerações o amor ao trabalho sistematizado, o espírito de observação (...) a atitude de questionar - digo eu - de rigorosa observação do paciente".

Falava de Perestrello, mas dizia de si mesmo. E este foi o seu legado.

Avelino Luiz RODRIGUES*

*Departamento de Psicologia Clínica do Instituto de Psicologia da Universidade de São Paulo. 